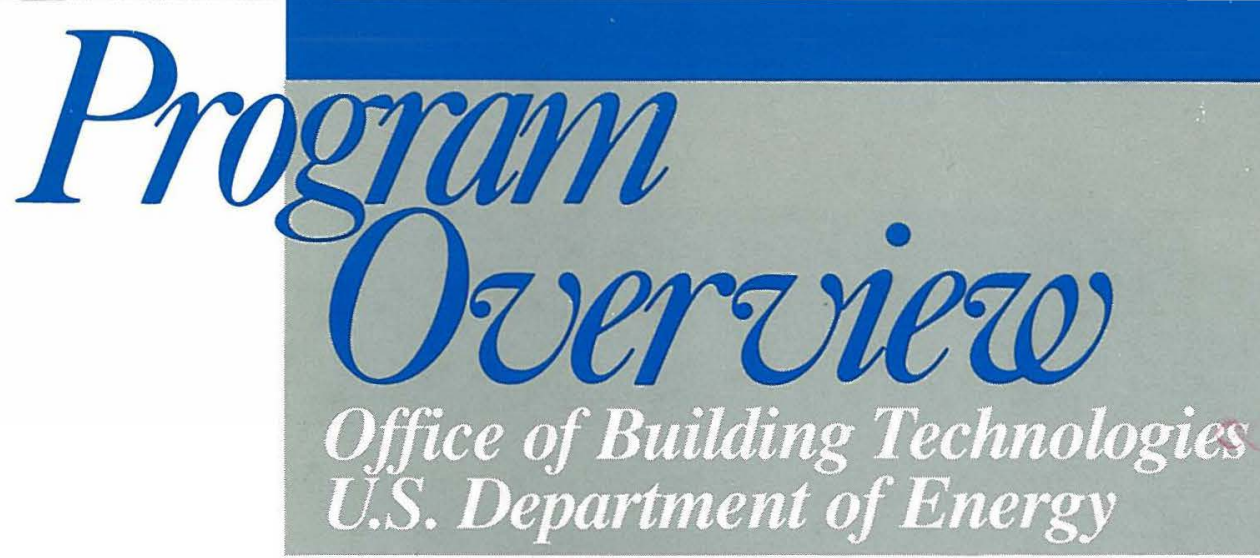

\title{
DOE-HUD Initiative: Making Housing Affordable through Energy Efficiency
}

\section{Overview}

A new collaborative program of the U.S. Department of Energy (DOE) and the U.S. Department of Housing and Urban Development (HUD) is a significant step toward making HUD-aided housing more comfortable and affordable through greater energy efficiency. The Initiative on Energy Efficiency in Housing combines DOE's technical capabilities and HUD's experience in housing assistance. Over the next decade, the energy savings potential of this initiative is estimated to be 150 trillion Btu (0.15 quad) per year, or nearly $\$ 1.5$ billion in annual energy costs.

As the National Energy Strategy points out, many property owners and managers face barriers to improving energy efficiency. They often lack adequate financial resources and appropriate management. In addition, they lack information about the costeffectiveness of energy-related retrofits, as well as their proper installation and alternative financing mechanisms.

Through the initiative, DOE and HUD are working together to remove these barriers. The initiative is jointly managed by the HUD Assistant Secretary for Community Planr and Development and the DOE Assistant Secretary for Conservation and Renewable Energy, through an interagency steering committee.

\section{Program Goals and Strategy}

The goals of the DOE-HUD Initiative on Energy Efficiency in Housing are to:

- Make housing more affordable and comfortable through energy-efficiency improvements in HUD programs

- Apply existing technical information on energy efficiency to HUD-assisted housing construction and retrofit activities

- Reduce federal outlays for utility expenditures

- Demonstrate financial strategies that use resources of both the public and private sectors and substantially benefit all parties.

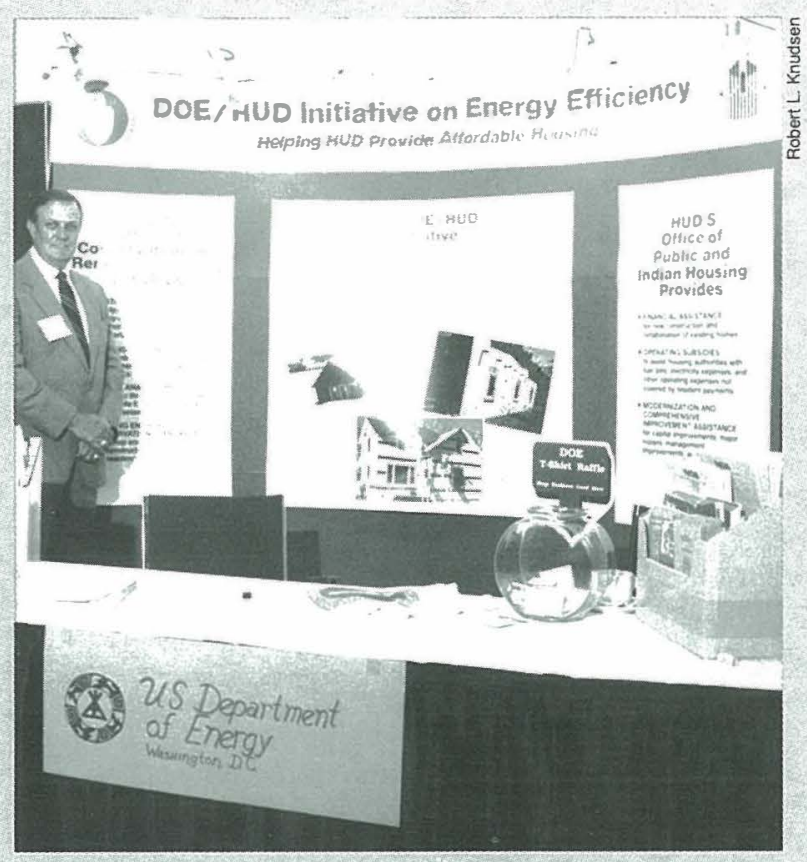

One event under the DOE-HUD initiative involved creating an exhibit booth to disseminate energy-related information to indian housing officials at the 1990

National American Indian Housing Council convention and trade show.

The strategy for the DOE-HUD initiative emphasizes financial and technical linkages, information dissemination, and revision of HUD programmatic guidelines and regulations to encourage energy efficiency. The initiative promotes the application of existing energysaving technology and techniques. Federal resources will be focused on those HUD programs with the highest potential for significant impact during this limited time.

\section{Program Implementation}

The DOE-HUD initiative is planned as a 4 -year program to be funded annually. High priority will be given to activities that leverage funding from other sources, such as utilities and state and local governments. The following eight startup projects were included in the 1990 budget: 


\section{DOE-HUD Initiative: Making Housing Affordable through Energy Efficiency}

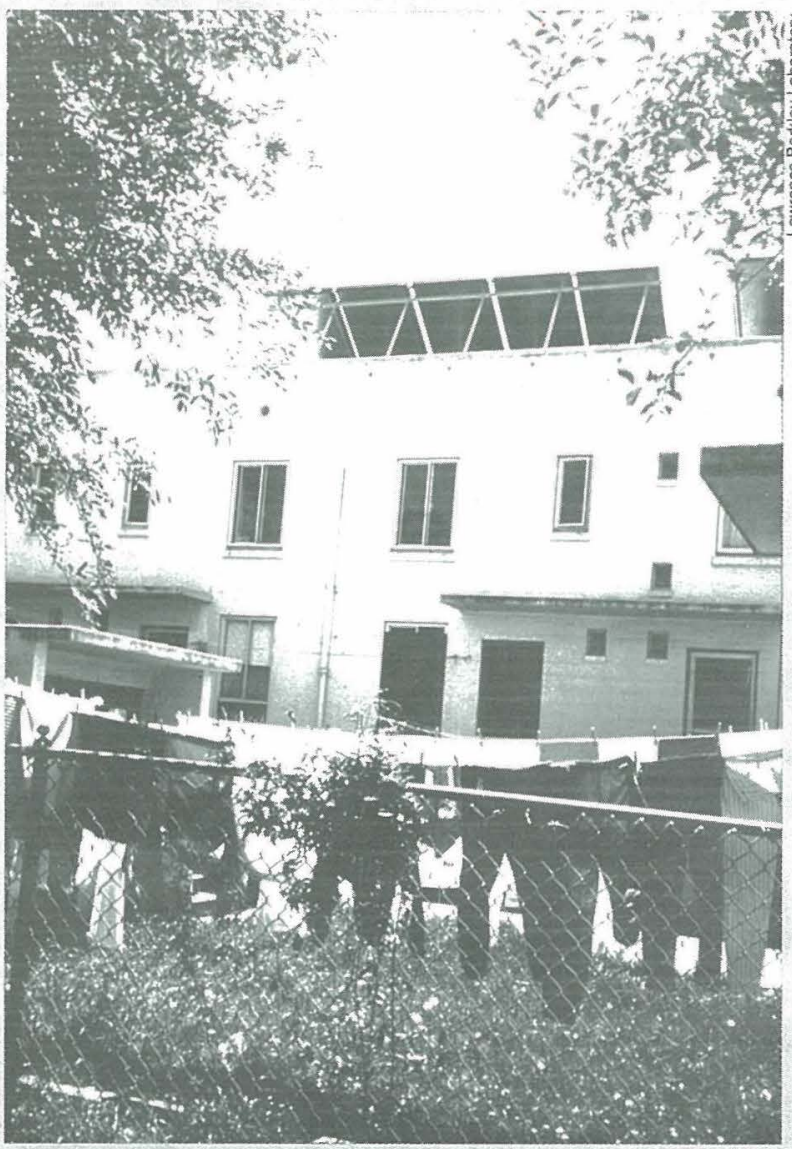

This joint DOE-HUD demonstration project in San Francisco studled the energy saved by retrofitting solar hot water systems paid for by a third-party financing arrangement.

\section{- Public Housing}

Performance contracting manual and outreach

Durability of retrofit savings in public housing

\section{- Single Family}

Rehabilitation property video and guide

Manufactured housing thermal testing

Indian housing design guide

Homeless shelter design guide

\section{- Multifamily}

Multifamily property disposition guidelines

Elderly housing retrofit demonstration (Section 202)

Four FY 1991 projects are also under way through the DOE Support Offices in Kansas City; Chicago; Boston; and Richland, Washington.

\section{Contact}

For more information about DOE's activities in the DOE-HUD Initiative on Energy Efficiency in Housing, contact:

Ernest C. Freeman

Building Systems and Materials Division, CE-421

U.S. Department of Energy

Forrestal Building, Room 5E-098

1000 Independence Avenue, SW

Washington, DC 20585

(202) $586-9192$

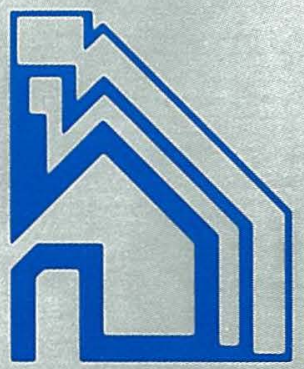

